\title{
Creando resiliencia en la comunidad a través de las plataformas digitales. El caso del Palacio Güell durante la pandemia
}

Creating resilience in the community through digital platforms. The case of The Güell Palace during the pandemic

\author{
Anaiis Barnolas Soteras
}

Palacio Güell. barnolassa@diba.cat

\begin{abstract}
Resumen
El Palacio Güell, edificio construido por Antoni Gaudí se vio obligado a trasladar sus actividades al formato digital durante la pandemia de la COVID19. Uno de los proyectos que el equipamiento, ubicado en el barrio del Raval de Barcelona, llevo a cabo fueron las videoconferencias, especialmente dirigidas a los usuarios de los centros de la tercera edad del entorno. El objetivo fue el de mejorar el bienestar emocional de las personas mayores, una de los colectivos más afectados por el confinamiento.

La actividad consistió en descubrir el edificio a través de una visita virtual guiada y con el soporte de fotografias antiguas de la familia Güell y del servicio. La visita se planteó para que fuera entretenida y didáctica. Por eso, se potenció la explicación de la vida cotidiana del espacio, así como las anécdotas relacionadas con las personas que vivieron o trabajaron en él. Esta actividad tiene el objetivo de garantizar la accesibilidad del equipamiento y permitió recuperar el vínculo con el público de gente mayor que no podía visitar el edificio físicamente.
\end{abstract}

Palabras clave: gente mayor, brecha digital, Raval, visita virtual, accesibilidad

\footnotetext{
Abstract

The Güell Palace, a building built by Antoni Gaudi, was forced to transfer its activities to digital format during the COVID-19 pandemic. One of the projects that the equipment, located in the Raval neighborhood of Barcelona, carried out were videoconferences, especially aimed at users of the centers for the eldery in the area. The objective is to improve the emotional well-being of the elderly, one of the groups most affected by confinement.

The activity consisted of discovering the building through a virtual guided tour and with the support of old photographs of the Güell family and the servants. The visit was planned to be entertaining and educational. For this reason, the
} 
explanation of the daily life of the space was promoted, as well as the anecdotes related to the people who lived or worked in it. This activity has the objective of guaranteed the accessibility of the equipment and made it possible to recover the bond with the public of older people who could not physically visit the building.

Keywords: older people, digital divide, Raval, virtual tour, accessibility 


\section{Introducción}

El Palacio Güell, edificio construido por Antoni Gaudí entre 1886 y 1890, se sitúa en el origen de la arquitectura de la art nouveau a nivel mundial. El empresario Eusebi Güell le encargó a un joven arquitecto de 33 años construir su residencia familiar y le dio plena libertad creativa. La construcción tenía que disponer de una sala de conciertos y convertirse en el escenario de la vida social y cultural de uno de los hombres más ricos y cultivados del país.

El palacio se ubicaría en el barrio del Raval de Barcelona, delimitado por la calle Pelai, la Rambla, las rondas de Sant Antoni y Sant Pau y el puerto. En aquella época la burguesía empezaba a construir sus residencias en el barrio del Ensanche, pero Eusebi Güell decidió instalarse en el Casco Antiguo y la razón la encontramos en un corredor que comunica el Palacio Güell con la antigua Casa Güell, residencia de su padre, el industrial Joan Güell.

A causa de una serie de pleitos con los vecinos, el matrimonio formado por Eusebi Güell y Isabel López (hija del marqués de Comillas, Antonio López) se vio obligado a dejar su residencia de entonces, el Palacio Fonollar. Eusebi Güell compró las fincas que había al lado de la casa que había heredado de su padre, ubicada en La Rambla y las derribó para construir su palacio en la Calle Conde del Asalto — actual Nou de la Rambla—. La calle, con más de 230 años de historia, se caracteriza por su estrechez y poca luminosidad.

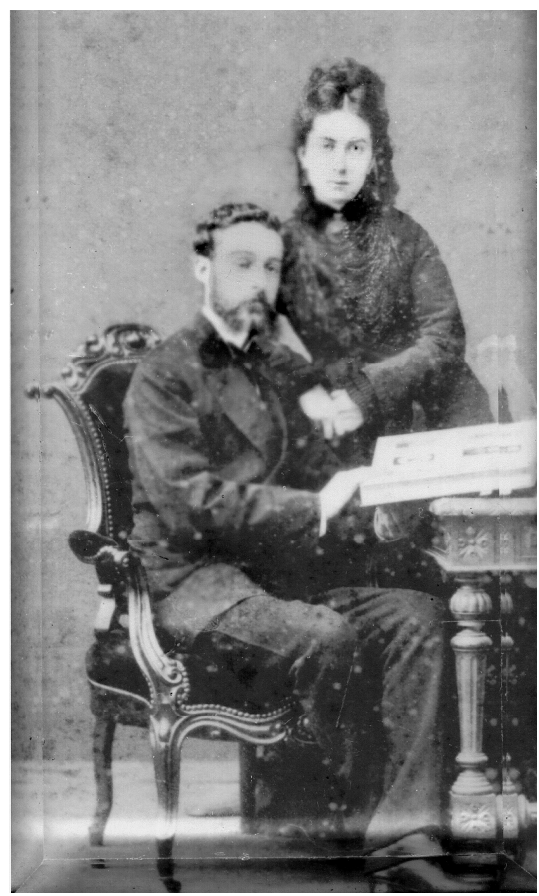

Fuente: Familia Güell de Sentmenat

Fotografía 1: Matrimonio Güell-López 
El encargó supuso un reto para Gaudí, que entonces la Casa Vicens y el Capricho de Comillas eran las obras de más envergadura que había construido. La residencia se ubicaría en una zona que destacaba por su vida popular y bohemia y, en cambio, tenía que responder a las exigencias de una vivienda señorial. A pesar de las dificultades, el arquitecto consiguió hacer de la necesidad virtud y organizó todo el edificio hacia dentro para que la vida interior del palacio quedara aislada de la de la calle. Esta habilidosa disposición del espacio permitió dominar magistralmente el tratamiento de la luz interior (con la singular incorporación de la música como elemento esencial). El otro aspecto que hizo del palacio un edificio único en su momento fue la utilización de un lenguaje innovador relacionado con el dominio de las técnicas constructivas tradicionales (González, Lacuesta, 2013).

Desde 1945 el edificio pertenece a la Diputación de Barcelona, que se ocupa de su conservación, preservación y difusión. En 1984 fue inscrito en la lista del Patrimonio Mundial de la UNESCO por su valor universal excepcional. Es uno de los bienes patrimoniales mejor conservados del arquitecto, puesto que no ha sufrido modificaciones esenciales. El edifico es un laboratorio de experimentación de técnicas arquitectónicas que Gaudí continuó desarrollando en sus obras posteriores como en la cripta de la Colonia Güell, la Casa Milà o la Casa Batlló. El Palacio Güell es una pieza clave, junto con el resto de obras gaudinianas, para comprender la obra del arquitecto en su totalidad.

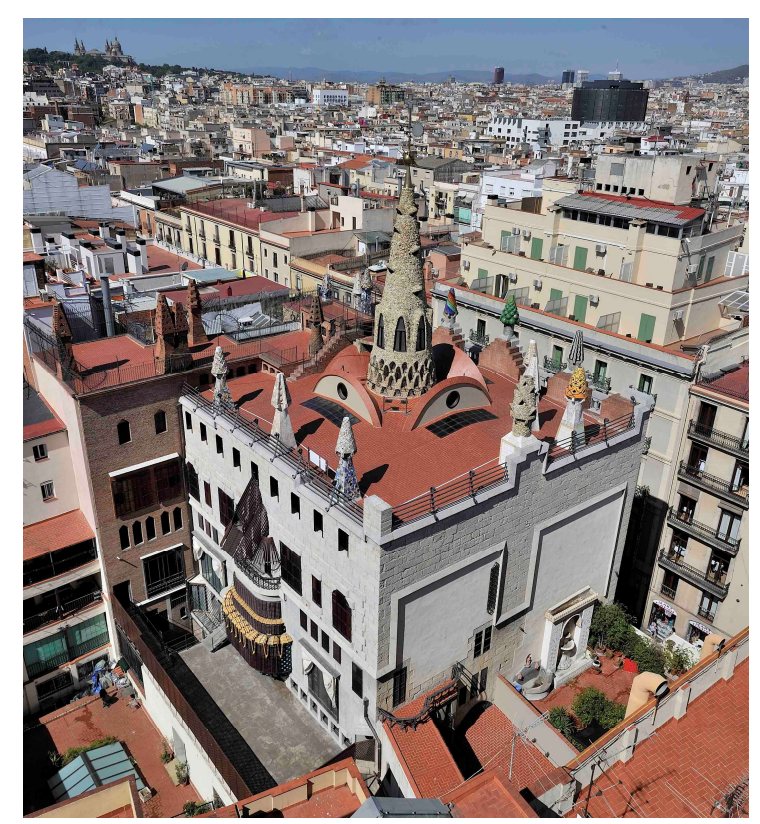

Fuente: Montserrat Baldomà/Diputación de Barcelona

Fotografía 2. El Palacio Güell

Actualmente se pueden visitar las siete plantas prácticamente de manera íntegra. Antes de la pandemia recibía una media de 700 personas al día. Los principales visitantes eran franceses 
(30\%) y estadounidenses (12,5\%). Cabe destacar que únicamente un $7 \%$ procedía del Estado español, por lo tanto, ocupaba el décimo puesto en las nacionalidades de los visitantes. La crisis sanitaria revertió estas estadísticas y como sucedió en el resto de equipamientos culturales de la ciudad, los principales visitantes pasaron a ser de Barcelona y sus alrededores. Si en el año 2019 recibió un total de 204.744 personas, en el año 2020 la cifra fue de 39.729 , lo que supuso un descenso del $80,6 \%$.

\subsection{El Raval, uno de los barrios más vulnerables de Barcelona}

A finales del siglo XIX, cuando se construyó el Palacio Güell, el barrio era una zona donde se habían instalado las fábricas, los obreros y numerosos cafés, tabernas, fondas y establecimientos de recreo. Era un lugar bohemio y atractivo para los artistas. El pintor Pablo Picasso tenía su estudio en la misma calle Nou de la Rambla. Justo delante del Palacio Güell estaba el conocido cabaret Edén Concert que «fue considerado como la sede del libertinaje y el escándalo; un centro de perdición, eso sí, montado con gran lujo» (Villar, 1996). En aquellos años, el Raval abarcaba los bajos fondos de la ciudad y en 1925 fue bautizado con el apelativo «Barrio Chino» por Francisco Madrid. El periodista describió un bar popular de entonces, La Mina, como «la gran taberna del barrio chino. Porque el distrito quinto, como Nueva York, como Buenos Aires, como Moscú, tiene su barrio chino» (Madrid, 2010), en relación con las afinidades que creía encontrar y lo que, al parecer, debió ver en las películas hollywoodienses o leer en reportajes periodísticos sobre el Chinatown de San Francisco o Nueva York.

El Raval continúa siendo un lugar atractivo para diseñadores y artistas y es uno de los barrios más interesantes culturalmente. Un 51,9\% del vecindario proviene de otras partes del mundo, como Pakistán, Filipinas o Bangladesh, lo que lo convierte en uno de los barrios más interculturales de Barcelona (Ayuntamiento de Barcelona, 2019), a diferencia de otras ciudades, donde este fenómeno se observa solo en las periferias. También es el que concentra más equipamientos culturales de la ciudad. En concreto, más de 300, como el Gran Teatro del Liceo, la Filmoteca, el Museo de Arte Contemporáneo de Barcelona (MACBA) o el Centro de Cultura Contemporánea de Barcelona (CCCB). Esta realidad convive con otra de muy distinta. Es uno de los barrios que, desde los Juegos Olímpicos de 1992, está sufriendo más la gentrificación por el aumento del precio de venta y alquileres de viviendas, locales comerciales y licencias de actividades (Fernández, 2014). Se sitúa entre los diez barrios donde el porcentaje de pisos para uso turístico sobre el total de domicilios es más elevado y, asimismo, donde el incremento del precio medio de alquiler es mayor. Muchos de los vecinos habitan en viviendas antiguas, degradadas, sobrepobladas y se ven sujetos a pagar un alquiler que está por encima de sus posibilidades (Ayuntamiento de Barcelona, 2018). 


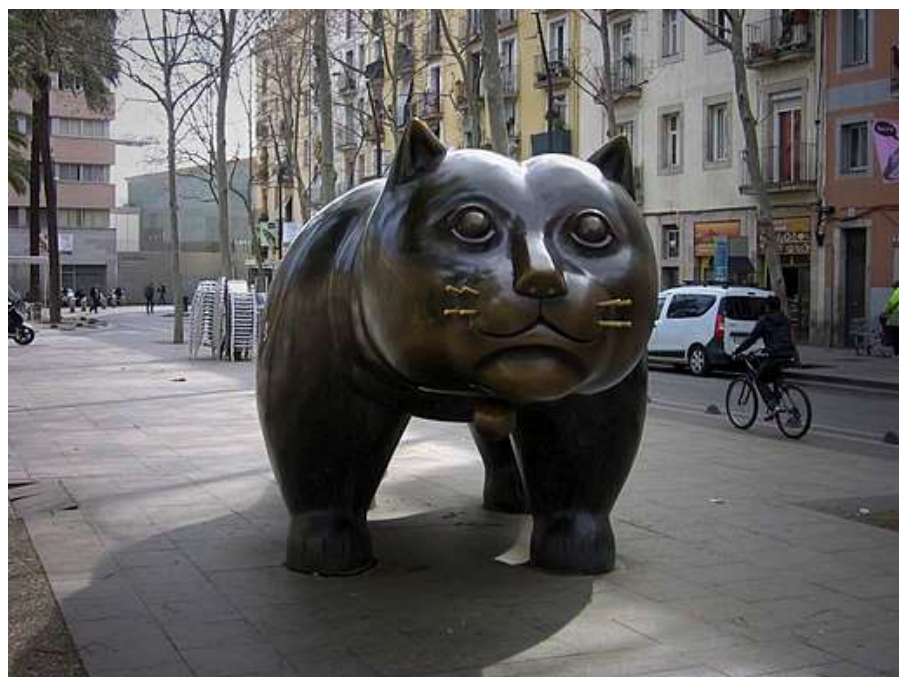

Fuente: Wikipedia/ Tokota

Fotografía 3. El gato de Botero ubicado en la Rambla del Raval y que se ha convertido en uno de los símbolos de referencia del barrio.

La renta per cápita de la población del Raval es baja (8.988€) en comparación con la media de Barcelona (15.755 €) (Ayuntamiento de Barcelona, 2017), y la situación económica de muchos vecinos es de precariedad e inestabilidad laboral. Algunos de ellos trabajan en la economía sumergida o en condiciones de abuso laboral (Ayuntamiento de Barcelona 2020).

La pandemia ha incrementado y ha puesto más de manifiesto estas desigualdades sociales. El Raval ha sido el barrio con un crecimiento más fuerte del paro registrado (48,8 \%), con diferencias de más de siete puntos respecto al distrito de Ciutat Vella, al que pertenece $(41,8$ \%) (Ayuntamiento de Barcelona, 2020). En la segunda ola fue el barrio que tuvo más incidencia y riesgo de contagio del coronavirus, junto a Nou Barris y el Besós, poniendo de manifiesto la relación entre la afectación de la COVID-19 y los barrios con las rentas más bajas (Marí-dell’Olmo, Gotsens, Pasarín, Rodríguez-Sanz, Artazcoz, Garcia de Olalla, Rius Borrell, 2021).

No obstante, con la crisis provocada por la emergencia sanitaria, el barrio del Raval ha vuelto a demostrar su resiliencia. Cuando empezó el confinamiento, ya existía una estructura horizontal con la red de soporte mutuo creada por los vecinos y que permitió ayudar a los más desfavorecidos.

\subsection{Las personas mayores en el Raval}

Las personas mayores fueron un grupo de alto riesgo cuando todavía no estaban vacunadas de la COVID-19. Además de los problemas de salud que la enfermedad ocasionó y los miedos 
que suscitó, las relaciones interpersonales cambiaron drásticamente durante el confinamiento. Las medidas de seguridad para no contraer la COVID-19, como el distanciamiento social o bien el poco dominio de las nuevas tecnologías, incrementaron su sensación de aislamiento social y soledad emocional. Como consecuencia, la salud psicológica y emocional se vio seriamente afectada y sus efectos aún persisten. Sobre todo, para las personas que viven solas y que tienen un nivel socioeconómico bajo, como es la situación en que se encuentra mucha de la población del barrio (Ayuntamiento de Barcelona, 2021).

En el Raval, las personas de más de 65 años que viven solas suponen un 31,8\%, cuando la media de Barcelona está en 25,7 \% (Ayuntamiento de Barcelona, 2020). Además, cabe tener en cuenta que muchas de ellas viven en fincas sin ascensor, hecho que aún reduce más su movilidad.

Asimismo, el distrito de Ciutat Vella presenta el porcentaje más alto de riesgo de mala salud mental, tanto en hombres (26\%) como en mujeres (32\%). Y, si nos fijamos en las personas de más de 64 años, la prevalencia más alta después del distrito de Nou Barris (36\%) es la de Ciutat Vella (29\%) en el caso de los hombres. Mientras que en las mujeres es la de Ciutat Vella (37 \%) (Agencia de Salud Pública de Barcelona, 2016).

La situación de aislamiento social en personas mayores es superior cuando las rentas son bajas, como sucede en el Raval. Al mismo tiempo, la brecha digital también juega un papel importante. La gente mayor que la sufre no dispone de los dispositivos necesarios o desconoce cómo hacer uso de las nuevas tecnologías. En consecuencia, no puede relacionarse con las personas cercanas y esto genera soledad. Además, el hecho de no poder utilizar las nuevas tecnologías le provoca angustia y frustración.

\subsection{La brecha digital en el distrito de Ciutat Vella}

Durante el confinamiento el uso de internet en Barcelona se incrementó un $62 \%$. Actualmente tan solo un $8 \%$ de los hogares no dispone de conexión. Más de la mitad de estos hogares están formados por personas de más de 74 años. De hecho, un $35 \%$ de este colectivo afirma que nunca se ha conectado a internet y casi el $50 \%$ de ellos afirman que no tienen conexión porque no lo saben utilizar. Por lo tanto, podemos asegurar que uno de los factores más importantes de la brecha digital es el de la edad. (Ayuntamiento de Barcelona, 2021).

La renta y el nivel formativo, junto con la edad, continúan condicionando el tipo de acceso y el uso de las TIC. En los hogares con rentas bajas, como es el caso del barrio del Raval, el nivel de conexión en los últimos años ha pasado del $75 \%$ al $91 \%$; de esta manera se ha reducido a solo seis puntos la diferencia con los hogares de renta alta, que han pasado del $91 \%$ al $97 \%$. No obstante, en Ciutat Vella, un $30 \%$ de los encuestados afirman que el motivo es porque no se lo pueden permitir y el $45 \%$ que no les hace falta porque no utilizan internet. 
Por lo que respecta a la disposición del teléfono inteligente en la ciudad el 80,7 \% de las personas jubiladas o pensionistas disponen de uno. Sin embargo, en el caso de las personas de más de 75 años su disponibilidad decrece de manera acusada hasta el 66,2 \%.

\subsection{La relación con el barrio}

El 2013 se puso en marcha el proyecto educativo del equipamiento con el objetivo primordial de implicarse en la comunidad para crear vínculos de cohesión social con los vecinos y, en especial, con las personas en situación de vulnerabilidad ${ }^{1}$ (Diputación de Barcelona, 2018). Por lo que respecta a la gente mayor, actualmente organiza visitas guiadas sobre la historia del edificio. También se relaciona con los centros de la tercera edad Josep Tarradellas y Josep Trueta, ubicados en el Raval, a través del proyecto «Apadrina tu equipamiento cultural».

Este proyecto consiste en que un curso de una escuela o instituto del barrio apadrina un espacio cultural y expone sus necesidades y los contenidos que le interesaría trabajar. Dentro de este proyecto también se trabaja en aprendizaje-servicio (ApS) con los alumnos del segundo curso del grado medio de Técnico en Atención a las Personas en Situación de Dependencia del Instituto Miquel Tarradell. El alumnado prepara la visita a un equipamiento cultural adaptada a las necesidades de un colectivo en situación de dependencia. Se planifica la actividad conjuntamente y se lleva a cabo. Los usuarios descubren el edificio, se divierten, y son una pieza clave en el aprendizaje. Ellos son voluntarios y sienten que están ayudando a los estudiantes en su profesionalización, hecho que refuerza su autoestima y demuestra como el arte y la cultura son valiosos instrumentos para el bienestar de las personas.

\subsection{El cambio de paradigma}

Los grupos de escolares, casales de verano y asociaciones como fundación Surt —que programa salidas culturales a mujeres recién llegadas al Estado español- durante la crisis sanitaria continuaron visitando el espacio, siguiendo las medidas de restricción para prevenir la COVID-19. Pero la gente mayor dejó de visitar el equipamiento y no se encontraba entre el público digital que utiliza las redes sociales y el web —el público de más de 65 años que consulta el web es de solo un 5,5\% y en Facebook los seguidores son de un $10 \%$ (mujeres) y $3 \%$ (hombres) - Los referentes de los centros de gente mayor nos confirmaron esta hipótesis, puesto que los usuarios se encuentran en la fase inicial de las nuevas tecnologías. La mayoría como mucho buscan información a través del buscador Google, pero no visitan webs ni están presenten en las redes sociales.

\footnotetext{
${ }^{1}$ Esta es la misión del Plan de Gestión del Palacio Güell (2018-2022) que toma como referencia la Convención sobre la protección del Patrimonio Mundial Cultural y Natural (UNESCO, 1972). En el contexto de pandemia, cabe tenir en consideración el articulo 5 que señala la implicación que el patrimonio cultural debe tener en la vida de las comunidades. La UNESCO define el papel de los museos como un motor de mejora de la integración social de las poblaciones vulnerables y cómo el museo puede ayudar a las comunidades a hacer frente a cambios profundos de la sociedad, como los que provocan más desigualdad (UNESCO, 2015).
} 
En lo que concierne al proyecto «Apadrina tu equipamiento cultural», los estudiantes asistieron en persona a las reuniones de trabajo en el Palacio Güell, pero implementaron la visita guiada sin los usuarios - solo con los compañeros de clase-, al considerarse un colectivo de riesgo, y las actividades con la gente mayor se trasladaron al formato online.

\section{Objetivos}

El Palacio Güell tiene como prioridad llegar al público local y, en concreto, el de más de 65 años, ya que es un público potencial ${ }^{2}$. Si el equipamiento cultural quiere ser un agente social, también debe tener en cuenta a los públicos que no se pueden desplazar, como representan las personas mayores con movilidad reducida.

La pandemia solo ha hecho que poner de manifiesto la necesidad de los museos de romper las barreras físicas. Por este motivo, el Palacio Güell propuso ofrecer videoconferencias a los usuarios de los centros de gente mayor de Barcelona (en especial, al Josep Tarradellas y Josep Trueta) que más estaba padeciendo la soledad.

Los objetivos de las visitas telemáticas son:

- Promover la actividad social y cultural con la finalidad de mejorar su bienestar emocional.

- Aprender y divertirse.

- Ofrecer las herramientas necesarias para que puedan ser autónomos a la hora de visitar el web del Palacio Güell (la visita virtual) por su cuenta, ya que las trabajadoras sociales de las residencias afirman que muchas veces el problema no es solo carecer de las herramientas — en este caso, de un teléfono inteligente, que es lo mínimo indispensable-, sino desconocer el cómo emplearlas.

- Reservar un espacio para que los usuarios pongan en valor sus vivencias, experiencias y recuerdos como parte de la memoria colectiva del barrio.

- Tejer vínculos.

\section{Programa de la innovación}

La primera videoconferencia se llevó a cabo el 10 de marzo, con motivo del Día de la Mujer. La sesión trató sobre las mujeres que habitaron en el Palacio Güell, tanto por parte de la familia Güell como de las niñeras, cocineras y camareras que trabajaron en él. A medida que se enseñó el edifico a través de la visita virtual, se comentaron los espacios relacionados con los usos sociales y culturales que tuvieron.

\footnotetext{
${ }^{2}$ La previsión és que en 2050 una de cada seis personas en el mundo tendrá más de 65 años (16\% de la población) en comparación con las estadísticas del 2019 que son cada una de cada 11 (9\%) (ONU, 2019).
} 


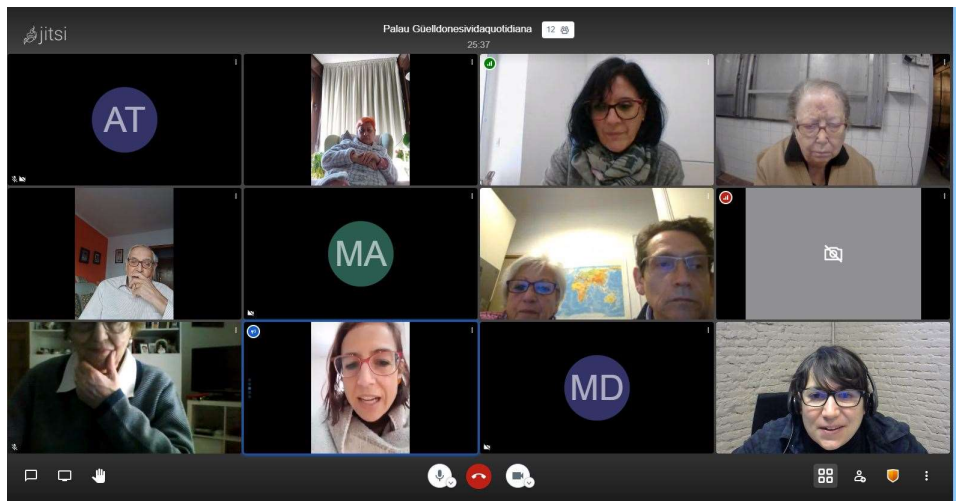

Fotografía 4. Videoconferencia el 10 de marzo con los usuarios del centro de gente mayor Josep Tarradellas y Josep Trueta.

La visita telemática se complementó con fotografías antiguas, con la finalidad de estimular los recuerdos y para que la sesión fuese participativa. En total, asistieron diez personas de los centros de gente mayor Josep Tarradellas y Josep Trueta.

La sesión, de una hora de duración, se hizo a través de la plataforma Jitsi, porque es la que los usuarios tienen más familiarizada y no implica descargar ni instalar ningún programa informático. La actividad empezó con una introducción al edificio y a las personas que trabajaron y vivieron en él. La mayor parte de la visita consistió en explicar las salas que los usuarios iban viendo y comentando a través de la visita virtual. La segunda parte de la sesión se basó en mostrar fotografías de la decoración original del edificio. Por último, los usuarios pusieron en común la valoración de la visita y pudieron exponer sus impresiones y preguntas al respecto.

El 18 de mayo, con motivo del Día Internacional de los Museos, organizamos una visita presencial para los usuarios de los centros de gente mayor Josep Tarradellas y Josep Trueta, que, al estar ya vacunados de la COVID-19, se animaron a asistir presencialmente.

Por lo que respecte al proyecto «Apadrina tu equipamiento cultural», los dos grupos de estudiantes del instituto Miquel Tarradell, tanto el turno de la mañana como el de la tarde, grabaron con sus móviles una visita guiada que hicieron llegar al centro Josep Tarradellas y a la residencia Vigatans. Por lo tanto, se mantuvo el vínculo intergeneracional y las personas mayores continuaron formando parte del aprendizaje de los estudiantes.

En los próximos meses se espera poder ofrecer esta actividad a más entidades. Por ejemplo, a Taller Sant Jordi — asociación que trabaja con personas con disminución psíquica—o a la residencia Mil·lenari que está en la misma calle del Palacio Güell. También se ha contactado con la fundación Tot Raval, entidad que tiene relación con todas las organizaciones del barrio, para difundir la actividad. 
Cabe destacar que el Palacio Güell ha realizado más videoconferencias a gente mayor, dentro del ciclo «Los museos te visitan» impulsado por el grupo de trabajo «Museos y Accesibilidad». La agrupación, creado en el 2013, está formado por distintos referentes de museos de los ámbitos de la accesibilidad y los servicios educativos y del cual el Palacio Güell forma parte. Durante la pandemia se ha creado un subgrupo para ofrecer actividades a la población de gente mayor y a los colectivos vulnerables. En coordinación con este grupo de trabajo, hasta el mes de junio de 2021, el Palacio Güell ha realizado las siguientes visitas:

- 3 de marzo, dirigida a los usuarios del proyecto VinclesBCN. El servicio, de la Área de Derechos Sociales del Ayuntamiento de Barcelona, presta a las personas mayores una tableta con conexión a internet para poder relacionarse con otras personas. 10 participantes.

- 7 de abril, dirigida a los usuarios de la Asociación de Familiares de Alzheimer de Barcelona. 6 participantes.

- 13 de mayo, dirigida a los usuarios de los centros de gente mayor de Barcelona. 5 asistentes.

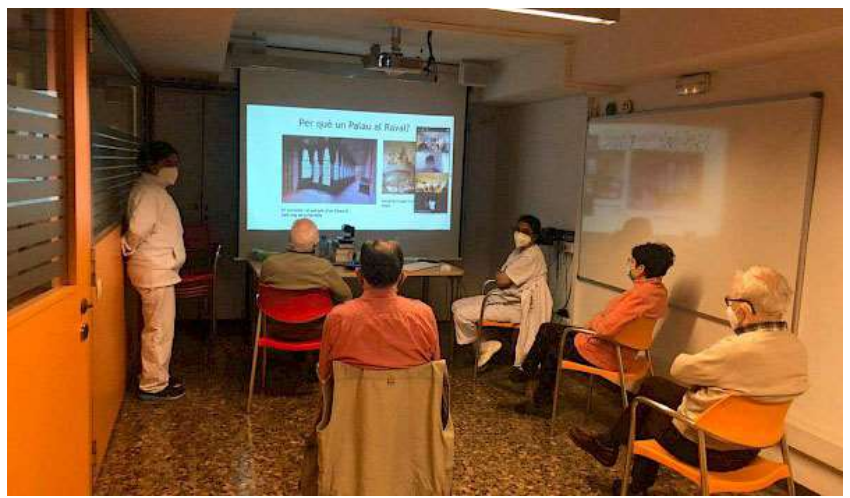

Fotografía 5. Videoconferencia que tuvo lugar el 7 de abril, dirigida a los usuarios de la Asociación de Familiares de Alzheimer de Barcelona

\subsection{La visita virtual}

La visita virtual del Palacio Güell se distingue de otras muchas que se pueden consultar en la red por la gran calidad de detalle de las imágenes para poder apreciar el trabajo de las artes aplicadas como los artesonados, los arrimadores, las vidrieras o la piedra del edificio. Esto se ha conseguido mediante una técnica en que cada panorámica es el resultado de 21 fotografías realizadas desde el mismo ángulo, pero que se han expuesto a diferentes intensidades de luz. La unión de todas ellas y su posterior edición ha permitido reproducir las sombras y las luces sin las limitaciones que tiene la cámara fotográfica, por lo que se ha conseguido reproducir el mismo ambiente de la visita presencial. 


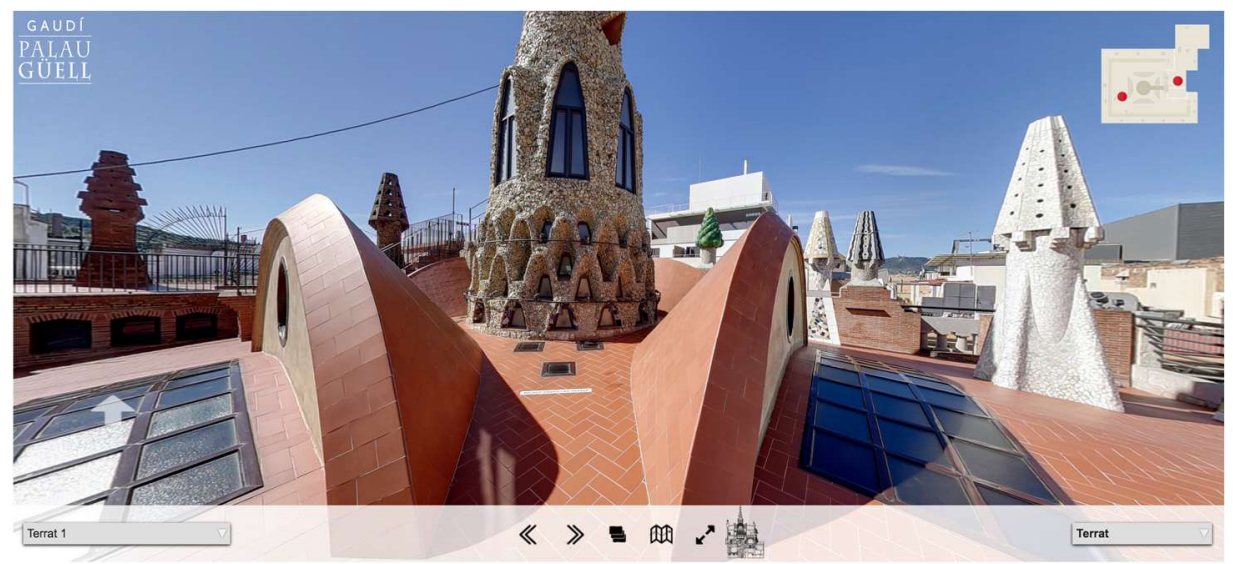

Fotografía 4. Imagen de la visita virtual en la azotea

Una de las impresiones que señalan los visitantes que acuden por primera vez al Palacio Güell es la complejidad que supone ubicarse en cada espacio. Esto se debe a la singularidad de la distribución del edificio, que es diferente a las residencias familiares tradicionales, debido a que todo él gira en torno al salón central. Por esta razón, en la visita virtual se ha añadido una sección longitudinal del edificio y un plano de cada planta para que los usuarios puedan ubicarse en todo momento.

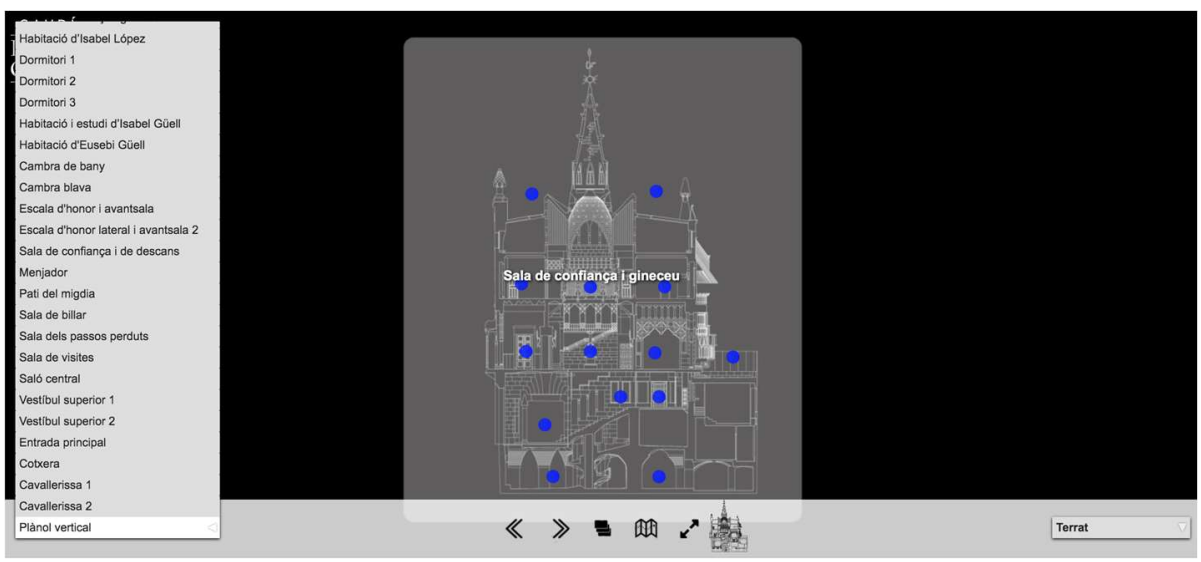

Fotografía 5. La sección horizontal de la visita virtual para que el público se ubique. Cuenta con dos desplegables: uno de las salas y el otro de las plantas. 


\section{Resultados}

Los resultados se han obtenido de la valoración cualitativa que han hecho los implicados al final de la sesión del 10 de marzo porque es con las entidades que se tiene más vinculo y se ha podido reflexionar más e intercambiar opiniones. La valoración es la siguiente:

\section{Usuarios:}

- Les permite tener contacto con otras personas, aunque sea de forma virtual.

- Se han entretenido y han aprendido no solo del contenido del espacio sino también herramientas de las nuevas tecnologías.

- Valoran mucho que una persona les haya explicado el edificio.

- Preferirían visitar el espacio presencialmente, siempre que las circunstancias lo permitan.

\section{Gestora cultural}

- El hecho de ofrecer estas visitas da sentido a la función social del equipamiento.

- El papel de las educadoras sociales es crucial. Pueden llamar a los usuarios que desde casa están teniendo problemas para conectarse y mediar si surge algún conflicto entre personas.

- Los contenidos no son lo esencial, sino la experiencia.

- Es importante conectarse antes de la hora de inicio de la actividad para ayudar a resolver problemas técnicos que puedan surgir y conocer a los usuarios.

- Los problemas técnicos que puedan surgir alteran la actividad y hay que responder a estos imprevistos.

\section{$\underline{\text { Persona referente de los centros de gente mayor: }}$}

- El contenido que se ha explicado ha sido demasiado. Mejor mostrar menos espacios y contar más anécdotas.

- Desde que los usuarios se conectan hasta que empieza la actividad se alarga demasiado la sesión (media hora más).

- Les gustaría que la actividad tuviera continuidad en forma de capítulos y que, luego, si se pudiera, se concluyera haciendo la visita presencial.

- Hay gente mayor que no se ha inscrito porque no dispone de un teléfono inteligente, de buena conexión en internet y, por lo tanto, de conocimientos tecnológicos suficientes para desarrollar la actividad.

- Valoran que no se haya utilizado un lenguaje técnico, así los usuarios pueden interiorizar y reproducir lo que han aprendido.

- Pese a haber enseñado a los usuarios cómo visitar virtualmente el edificio, ninguno lo ha consultado por su cuenta. 


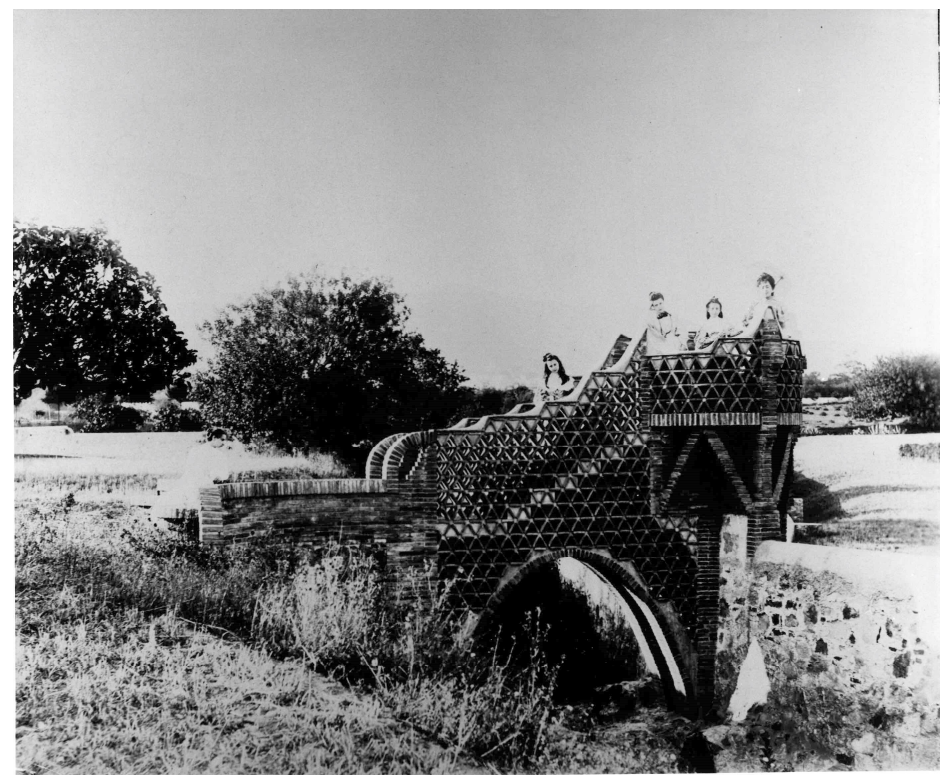

Fuente: Familia Güell de Sentmenat

Fotografía 6. Las hijas del matrimonio Güell-López en el Palacio de Pedralbes. Imagen que se muestra durante la actividad.

\section{Conclusiones}

La pandemia ha acelerado el proceso de digitalización de equipamientos y museos y el pronóstico es que las actividades online pasen a formar parte de la programación estable de equipamientos y museos junto con la modalidad presencial. Teniendo en cuenta que quizás muchas de las personas mayores no pueden ir físicamente a visitar el Palacio Güell, la incorporación de estas actividades digitales puede ser el modo de llegar a un público que queda excluido de la programación física del museo. No obstante, cabe destacar que la gente mayor prefiere visitar presencialmente el espacio, siempre que le sea posible.

Los usuarios han valorado muy positivamente la experiencia. Han conocido el edificio y, al mismo tiempo, se han familiarizado con las herramientas tecnológicas. Uno de los aspectos que más han remarcado es el factor humano, es decir, que una persona les haya explicado el edificio.

Las actividades digitales han permitido al palacio reestablecer el vínculo que había perdido con la gente mayor durante a la pandemia. Las visitas digitales han estado muy bien valoradas por todas las partes participantes. Desde el Palacio Güell se está trabajando para organizar un ciclo digital en que en cada visita trate una temática del espacio, en formato de capítulos para que las sesiones no sean densas de contenidos, no se vean demasiados espacios y que la sesión no se alargue más de lo debido. El ciclo terminaría con la visita presencial al edificio. 


\section{Referencias}

AGENCIA DE SALUD PÚBLICA DE BARCELONA. (2016). La salut mental a Barcelona, 2016. Barcelona: Ayuntamiento de Barcelona.

AYUNTAMIENTO DE BARCELONA (2020). Medida de gobierno. Ciutat Vella delante de la crisis producida por la Covid-19. Barcelona: Ayuntamiento de Barcelona.

AYUNTAMIENTO DE BARCELONA (2021). Barri del Raval. Districte de Ciutat Vella. $<$ https://www.bcn.cat/estadistica/catala/dades/inf/barris/a2018/barri1.pdf $>$ [Consulta: 19 de febrero de 2021]

AYUNTAMIENTO DE BARCELONA. (2021). La bretxa digital a la ciutat de Barcelona al 2020. Barcelona: Ayuntamiento de Barcelona.

AYUNTAMIENTO DE BARCELONA. (2020). L'estat de la situació per la Covid i el confinament a Barcelona. Barcelona: Ayuntamiento de Barcelona.

AYUNTAMIENTO DE BARCELONA. (2018). Informe sobre l'Habitatge a la ciutat de Barcelona. Consell Econòmic $i$ Social de Barcelona. Barcelona: Ayuntamiento de Barcelona.

DiPUTACiÓN DE BARCElONA. (2018). Pla de gestió del Palau Güell (2018-2022). Barcelona: Diputación de Barcelona.

FERNÁNDEZ, M. (2014). Matar al Chino. Barcelona: Virus editorial.

GONZÁleZ, A, LACUESTA, R. (2013). El Palacio Güell. Una obra maestra de Antoni Gaudi. Barcelona: Diputación de Barcelona.

MADRID, F. (2010). Sang a les Drassanes. Barcelona: Acontravent.

MARÍ-DELL'OLMO, M.; GOTSENS, M.; PASARÍN, MI.; RODRÍGUEZ-SANZ, M.; ARTAZCOZ, L.; GARCIA DE OLALLA, P.; RIUS, C.; BORRELL, C (2021). Socioeconomic Inequalities in COVID-19 in a European Urban Area: Two Waves, Two Patterns. Suecia: International Journal of Environmental Research and Public Health.

ONU (2019). The 2019 Revision of World Population Prospects. Nueva York: ONU.

UNESCO (1972). La Convención sobre la protección del Patrimonio Mundial Cultural y Natural. París: UNESCO.

UNESCO (2015). Recomendación relativa a la protección y promoción de los museos y colecciones, su diversidad y su función en la sociedad. París: UNESCO.

VILLAR, P. (1996). Historia y leyenda del Barrio Chino. Barcelona: La Campana. 